\title{
PREPARATION AND EVALUATION OF CHITOSAN SODIUM ALGINATE CARBAMAZEPINE MICROSPHERES
}

\author{
KARTHIKA RAMESH, KRISHNAPRIYA M, ASHA PAUL, SREEJA C NAIR*
}

Department of Pharmaceutics, Amrita School of Pharmacy, Amrita Institute of Medical Sciences and Research Centre, Amrita Vishwa Vidyapeetham, Amrita University, Kochi - 682 041, Kerala, India. Email: sreejacnair@aims.amrita.edu

Received: 12 November 2016, Revised and Accepted: 06 December 2016

\section{ABSTRACT}

Objective: The objective behind our study is that a mucoadhesive rectal hydrogel chitosan sodium alginate carbamazepine (CBZ) microspheres for the purpose of controlled release for the treatment of epilepsy to avoid the possible side effects.

Methods: The study was conducted to formulate controlled release chitosan sodium alginate CBZ microspheres with the dispersion of CBZ into the natural polymers chitosan and sodium alginate forming microspheres conducting along with their evaluation studies.

Results: The formulated microspheres were subjected to various evaluation parameters, and all the physical parameters examined are within the acceptable limits. Further, the optimized microsphere formulation (CM5) was characterized. Hence, the developed optimized microsphere formulation (CM5) seems to be a viable substitute to conventional drug delivery system for the effective management of epilepsy.

Conclusion: The prepared formulation also provides a desired CBZ loaded sodium alginate microspheres with the controlled release drug delivery.

Keywords: Carbamazepine, Sodium alginate microspheres, Particle size.

(C) 2017 The Authors. Published by Innovare Academic Sciences Pvt Ltd. This is an open access article under the CC BY license (http://creativecommons. org/licenses/by/4. 0/) DOI: http://dx.doi.org/10.22159/ajpcr.2017.v10i3.16145

\section{INTRODUCTION}

Epilepsy is a persistent long lasting medical neurological state or situation characterized by repeated, frequent and occasional seizures as a part of abnormal signal variation from neurons, affecting $1 \%$ of worldwide population. Excessive, subnormal or inordinate electrical discharges from nerve cells of brain cause these epileptic seizures. There are several reasons for epilepsy, leading to different types of epileptic seizures and syndromes, of which most common serious one is chronic epilepsy which may be caused due to brain tumors' or stroke. These seizures can be properly diagnosed and treated with appropriate anticonvulsant medication, while some cases need surgery. The treatment of epilepsy depends on several factors such as health, medical history, age of individuals, and severity and frequency of seizures caused. Hence, epileptic seizures should be properly diagnosed for selecting appropriate treatment [1]. Most of the anticonvulsant drugs are associated with side effects and these side effects are proportional to the doses of the drug, i.e., Higher the dose, greater will be the side effects. Hence, antiepileptic drugs should be started at low dose to reduce side effects [1-3]. Side effects also depend on type of medication and length of medication. Common side effects include fatigue, sleeplessness, weight gain stomach upset, blurred vision, hair loss, liver problems, gingivitis, and tremor. This work focuses on the preparation and evaluation of a mucoadhesive rectal hydrogel microspheres using a mixture of natural polymers for the purpose of sustaining the drug release for the efficient treatment and management of epilepsy so as to minimize the possible side effects.

\section{MATERIALS AND METHODS}

Materials

Carbamazepine (CBZ) was provided as a gift sample by Bajaj Private Limited, Mumbai, India. Chitosan was purchased from Central Institute of Fisheries and Technology, Kochi. India. All other materials used were of pharmaceutical grade.

\section{Preformulation studies}

For the rational development of drug dosage form, preformulation studies are considered as the preliminary and important step. The information and investigations obtained from these studies are designed to deliver important data's of drug-like physicochemical, physicomechanical, bio-pharmaceutical properties of drug substances and its excipients as well as its compatibility [4].

\section{Identification of drug}

Fourier transform infrared (FTIR) spectroscopy

FTIR of standard drug spectra (from monograph, Indian Pharmacopoeia) was compared with the obtained spectrum of the pure drug of CBZ.

\section{Solubility studies}

The drug (CBZ) solubility in different solvents such as water, ethanol, methanol, 1-propanol, 1-butanol, acetone, and in phosphate buffer pH 6.8 was determined.

\section{Melting point}

Purity of the obtained drug sample (CBZ) is marked by its melting point. Open capillary method is used to determine melting point of the drug. Lowering of melting point is seen in the presences of relative small amount of impurities.

\section{Partition coefficient}

Partition coefficient of CBZ in n-octanol water system was determined. Into a separating funnel, equal volume of n-octanol and water was taken then added a known amount of CBZ. Then, the funnel was shaken continuously for $2 \mathrm{hrs}$ at constant temperature, after $2 \mathrm{hrs}$ the aqueous layer was detected by ultraviolet (UV) spectroscopy. The partition coefficient is the ratio of amount of drug in organic or lipid layer to concentration of drug in aqueous phase [5]. 
$\lambda_{\max }$ of the CBZ in methanol

$\lambda_{\max }$ of CBZ was determined insolvent methanol. Standard stock solution prepared by following, for few minutes $50 \mathrm{mg}$ CBZ was sonicated and dissolved in $30 \mathrm{ml}$ methanol and volume was made up to $50 \mathrm{ml}$ mark using methanol. From the standard stock solution $(1000 \mu \mathrm{g} / \mathrm{ml})$, different aliquots were diluted with water separately to prepare a series of concentration from 8 to $18 \mu \mathrm{g} / \mathrm{ml}$. These were scanned from 400 to $200 \mathrm{~nm}$ using UV spectrophotometer [6,7].

\section{Analytical methods [8]}

Calibration curve of CBZ in methanol and phosphate buffer pH 6.8 was done.

\section{Calibration curve of CBZ}

a. Preparation of standard stock solution

About $50 \mathrm{mg}$ of CBZ was added to $30 \mathrm{ml}$ methanol and sonication for 10 minutes. The volume was made up to $50 \mathrm{ml}$ mark using methanol. The drug was dissolved and diluted to make a concentration of $1000 \mu \mathrm{g} / \mathrm{ml}$.

b. Preparation of standard graph:

From the above prepared stock solution $(1000 \mu \mathrm{g} / \mathrm{ml})$, different aliquots were withdrawn into $10 \mathrm{ml}$ standard flask and diluted with methanol separately to prepare a series of concentration from range 8 to $18 \mu \mathrm{g} / \mathrm{ml}$. The standard stock solution $(1000 \mu \mathrm{g} / \mathrm{ml})$ was scanned in the range of $400-200 \mathrm{~nm}$ against methanol as blank. Standard graph was obtained by plotting absorbance against concentration $(\mu \mathrm{g} / \mathrm{ml})[8,9]$.

Formulation of CBZ loaded chitosan sodium alginate microspheres (Fig. 1 and Table 1)

Characterization of CBZ chitosan sodium alginate microspheres [10-13]

The prepared microsphere was characterized for particle size, entrapment efficiency, in vitro drug release studies, scanning electron microscopy (SEM), etc.

\section{Particle size by optical microscopy}

Optical microscopic method (Olympus Opto System, India) is used for finding the size of microspheres.

\section{Entrapment efficiency [14]}

Determination of the concentration of entrapped drug is done by lysing the microspheres by sonication in phosphate buffer of $\mathrm{pH} 6.8$. Drug CBZ filled or loaded microspheres was exactly weighed and was dissolved in $25 \mathrm{ml}$ of phosphate buffer of $\mathrm{pH} 6.8$, sonicated the solution

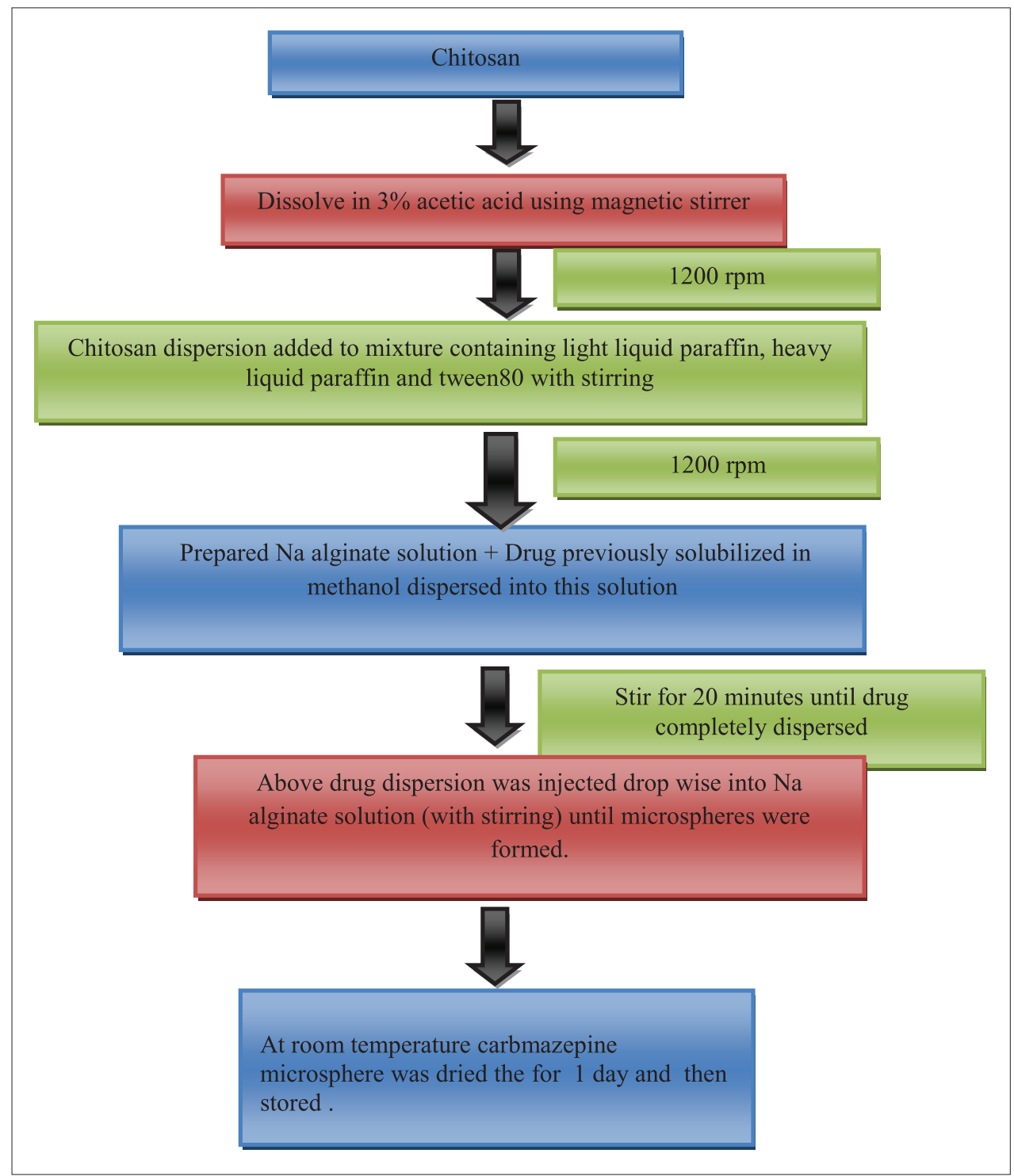

Fig. 1: Preparation of carbamazepine chitosan sodium alginate microspheres 
for 15 minutes and then extracted for $12 \mathrm{hrs} .1 \mathrm{ml}$ aliquot of this solution was then dissolved in $10 \mathrm{ml}$ of phosphate buffer $\mathrm{pH} \mathrm{6.8,} \mathrm{then}$ spectrometrically determined the concentration of loaded drug CBZ in phosphate buffer of pH 6.8 at $285.5 \mathrm{~nm}$. Each sample was examined in triplicate.

\section{In vitro release studies of drug [15-17]}

Drug discharge from loaded microsphere in in vitro studies was done using USP - Type II paddle dissolution apparatus. For studying the percentage drug release from prepared microspheres, CBZ loaded microsphere was accurately weighed from each batch and was taken in $900 \mathrm{ml}$ of dissolution medium (phosphate buffer $\mathrm{pH}$ 6.8). The solution as stirred at $100 \mathrm{rpm}$ by maintaining $37 \pm 0.5^{\circ} \mathrm{C}$ as temperature. Aliquots of $5 \mathrm{ml}$ solution were periodically withdrawn at regular intervals, for determining the concentration of the drug, at the same time $5 \mathrm{ml}$ was replaced with blank which was also analyzed spectrophotometrically at $285.5 \mathrm{~nm}$ release studies were carried out in triplicate.

\section{SEM $[18,19]$}

With an adhesive carbon tape, the optimized or the perfect microsphere formulation was mounted on an aluminum stub after diluting it with distilled water, it was sputter-coated with gold using a vacuum evaporator and examined in SEM for 5-10 minutes at $40 \mathrm{~mA}$ and then investigated at $30 \mathrm{kV}$.

\section{RESULTS AND DISCUSSION}

Preformulation studies

FTIR spectroscopy

FTIR of obtained pure drug CBZ in Fig. 2 was found to be in conformity with the monograph (IP) (Fig. 3).

\section{Solubility studies}

The pure drug is partially soluble in water and ethanol and completely soluble in methanol, phosphate buffer $\mathrm{pH} 6.8$ as mentioned in Table 2.

\section{Melting point of the drug}

The drug was found to melt at a temperature of $188-193^{\circ} \mathrm{C}$ and it was in accordance with that of the reference.

Table 1: Formulation composition of CBZ chitosan Na alginate microspheres

\begin{tabular}{llllllll}
\hline S.No. & Ingredients & $\mathbf{C M}_{\mathbf{1}}$ & $\mathbf{C M}_{\mathbf{2}}$ & $\mathbf{C M}_{\mathbf{3}}$ & $\mathbf{C M}_{\mathbf{4}}$ & $\mathbf{C M}_{\mathbf{5}}$ & $\mathbf{C M}_{\mathbf{6}}$ \\
\hline 1 & Chitosan (g) & 1 & 1.5 & 2 & 2.5 & 3 & 3.5 \\
2 & CBZ (mg) & 60 & 60 & 60 & 60 & 60 & 60 \\
3 & Sodium alginate (g) & 3.2 & 3.2 & 3.2 & 3.2 & 3.2 & 3.2 \\
4 & Heavy liquid paraffin (ml) & 100 & 100 & 100 & 100 & 100 & 100 \\
5 & Light liquid paraffin (ml) & 50 & 50 & 50 & 50 & 50 & 50 \\
6 & Acetic acid 3\% (ml) & 15 & 151 & 15 & 15 & 15 & 15 \\
7 & Tween 80 (ml) & 1.5 & 1.5 & 1.5 & 1.5 & 1.5 & 1.5 \\
\hline
\end{tabular}

CBZ: Carbamazepine

Table 2: Comparison of solubility profile of pure drug with reference

\begin{tabular}{ll}
\hline Solvent & Solubility \\
\hline Water & - \\
Ethanol & - \\
Methanol & + \\
1-propanol & - \\
Acetone & + \\
1-butanol & - \\
pH 6.8 & + \\
\hline
\end{tabular}

\section{Partition coefficient}

The drug was found to be insoluble in water proving that it is highly lipophilic, by showing a partition coefficient value of 1.59 .

\section{$\lambda_{\max }$ CBZ in methanol}

The absorption maxima of CBZ in methanol was found to be $285 \mathrm{~nm}$ as shown in Fig. 4 which was in accordance with the official standard.

$\lambda_{\max }$ of CBZ in phosphate buffer $p H 6.8$

The absorption maxima of CBZ in $\mathrm{pH} 6.8$ phosphate buffer was found to be $285.5 \mathrm{~nm}$ (Fig. 5).

\section{Analytical method by UV spectrophotometer}

Preparation of calibration curve for CBZ in methanol

The standard graph gave a straight line which indicates calibration curve is linear in the concentration range of $8-18 \mu \mathrm{g} / \mathrm{mL}$. The calibration curves were shown in Table 3 and Fig. 6.

Preparation of calibration curve for CBZ in phosphate buffer pH 6.8

The calibration curve was linear in the concentration range of $3-18 \mu \mathrm{g} / \mathrm{ml}$. The calibration curves were shown in Table 4 and Fig. 7.

Formulation of CBZ chitosan sodium alginate microspheres The chitosan sodium alginate microspheres were prepared by injecting drug and sodium alginate mixture into already prepared chitosan

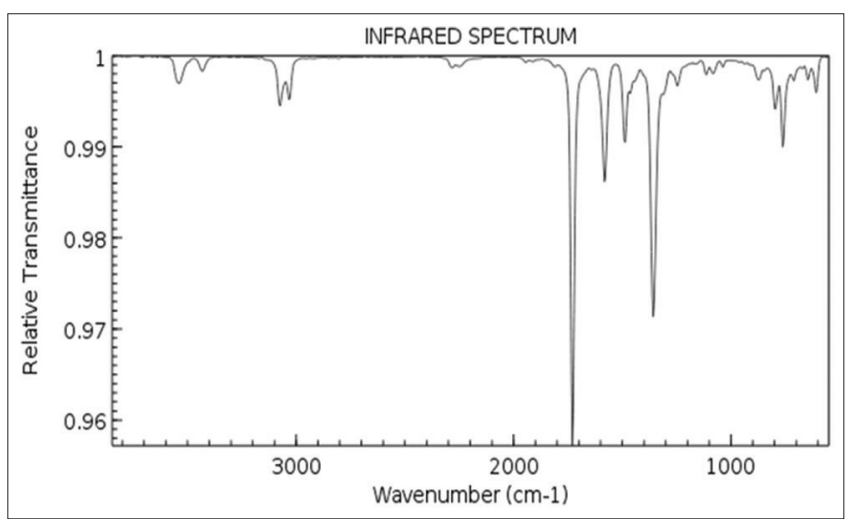

Fig. 2: Fourier transform infrared spectrum of carbamazepine according to monograph (IP)

Table 3: Absorbance value of CBZ in methanol

\begin{tabular}{lll}
\hline S.No & Concentration $(\boldsymbol{\mu g} / \mathbf{m L})$ & Absorbance $(\mathbf{n m})$ \\
\hline 1 & 8 & $0.522 \pm 0.01$ \\
2 & 10 & $0.637 \pm 0.02$ \\
3 & 12 & $0.745 \pm 0.03$ \\
4 & 14 & $0.854 \pm 0.02$ \\
5 & 16 & $0.968 \pm 0.47$ \\
6 & 18 & $1.01 \pm 0.03$ \\
\hline \multicolumn{2}{l}{ Values are expressed as mean \pm standard deviation, $\mathrm{n}=3}$.
\end{tabular}

Table 4: Absorbance value of CBZ in phosphate buffer pH 6.8

\begin{tabular}{lll}
\hline S.No. & Concentration $(\boldsymbol{\mu g} / \mathbf{m L})$ & Absorbance $(\mathbf{n m})$ \\
\hline 1 & 3 & $0.525 \pm 0.03$ \\
2 & 6 & $0.634 \pm 0.02$ \\
3 & 9 & $0.747 \pm 0.04$ \\
4 & 12 & $0.855 \pm 0.05$ \\
5 & 15 & $0.969 \pm 0.06$ \\
6 & 18 & $1.073 \pm 0.07$ \\
\hline \multicolumn{2}{l}{ Values are expressed as mean \pm standard deviation, $n=3}$. & CBZ: Carbamazepine
\end{tabular}




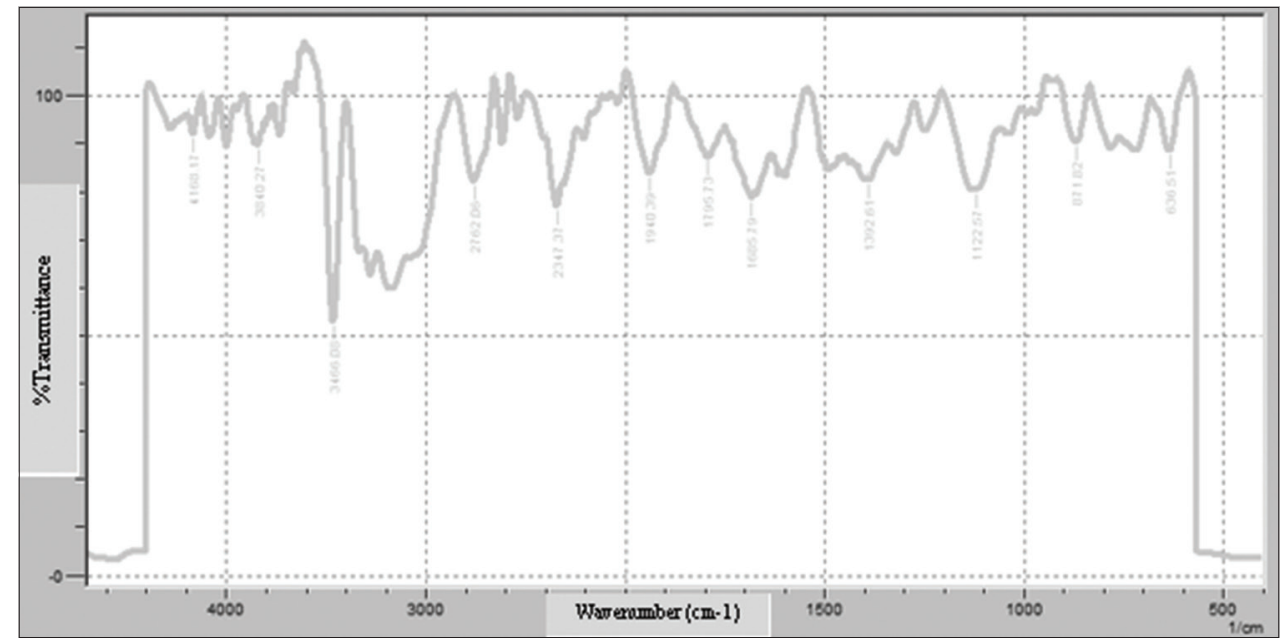

Fig. 3: Fourier transform infrared spectrum of sample carbamazepine active pharmaceutical ingredient

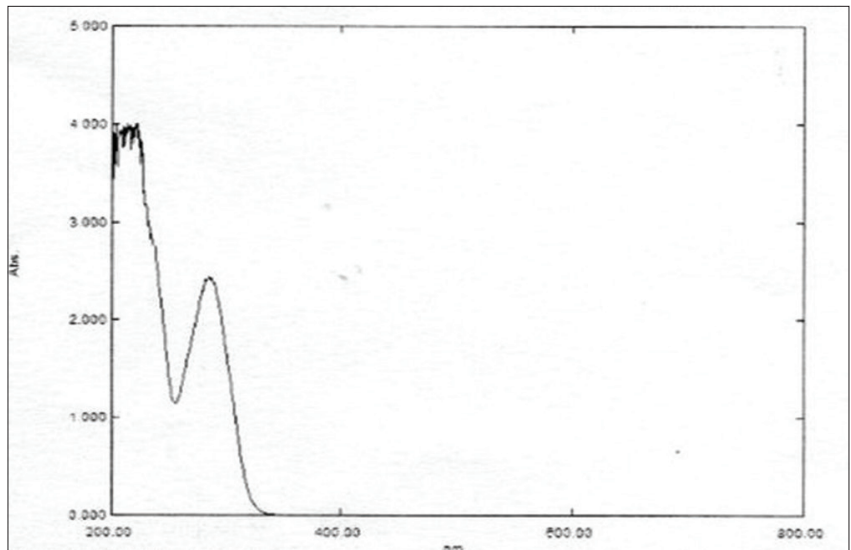

Fig. 4: Absorption maxima of carbamazepine in methanol

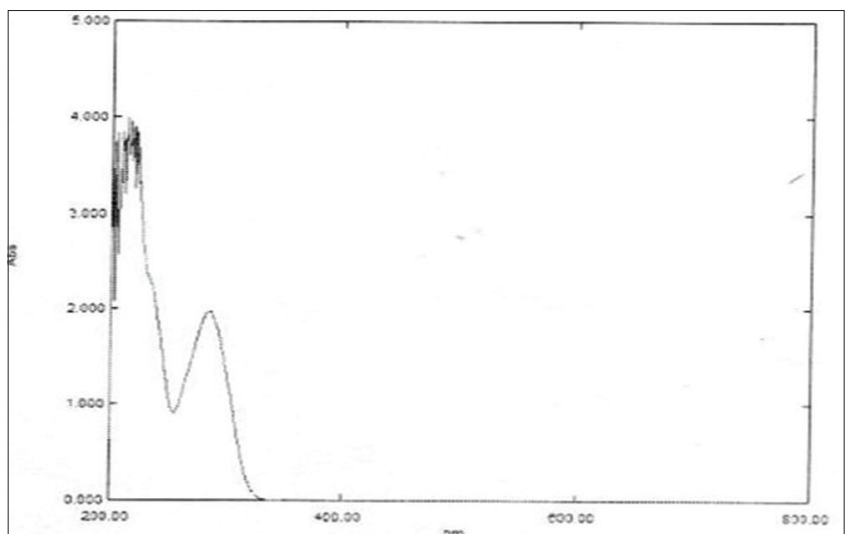

Fig. 5: Absorption maxima of carbamazepine in phosphate buffer pH 6.8

solution which contains light liquid paraffin, heavy liquid paraffin and SPAN 80. The prepared microspheres were filtered finally dried to obtain chitosan sodium alginate microspheres. The microspheres obtained were smooth and spherical in shape.

\section{Characterization of CBZ chitosan Na alginate microspheres}

Particle size by optical microscopy

The particle size of the microspheres was in the range between 70 and $100 \mu \mathrm{m}$.

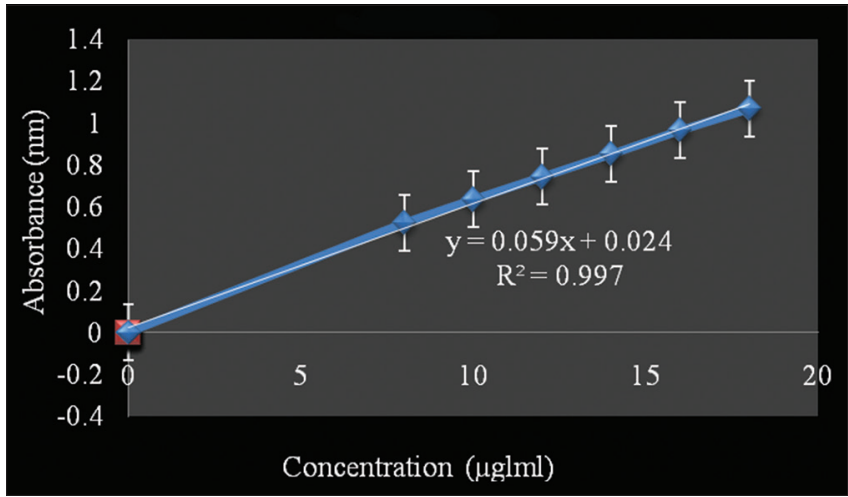

Fig. 6: Calibration curve for carbamazepine in methanol

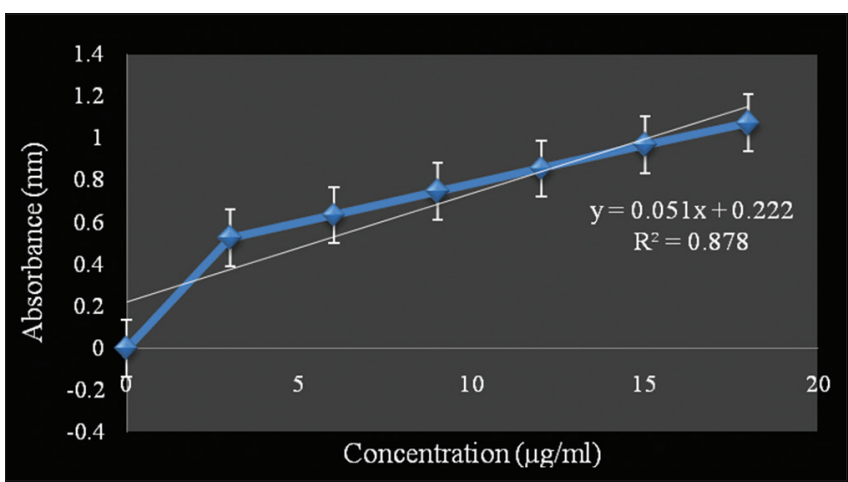

Fig. 7: Calibration curve for carbamazepine in phosphate buffer pH 6.8

\section{Entrapment efficiency}

Entrapment efficiency is the measure of solute retention. The entrapment efficiency of all microsphere formulations ranged between $62.67 \pm 0.29 \%$ and $92.56 \pm 0.72 \%$ as shown in Table 5 and Fig. 8 . The maximum entrapment efficiency was found to be $92.56 \pm 0.72 \%$ for microsphere formulation CM5. Entrapment efficiency of the drug in microsphere increases as polymer concentration is proportional to viscosity; higher polymer concentration means higher will be the viscosity. This lead to larger polymers/solvent droplets to be formed, and more will be the time for hardening of larger particles allowing time for drug diffusion out of the particles which tend to decrease drug release. 
Table 5: Entrapment efficiency of different microsphere formulations

\begin{tabular}{ll}
\hline Formulation code & $\begin{array}{l}\text { Percentage mean entrapment } \\
\text { efficiency (\%) }\end{array}$ \\
\hline CM1 & $65.34 \pm 0.53$ \\
CM2 & $67.56 \pm 0.45$ \\
CM3 & $71.12 \pm 0.49$ \\
CM4 & $84.23 \pm 1.67$ \\
CM5 & $92.56 \pm 0.72$ \\
CM6 & $62.67 \pm 0.29$ \\
\hline
\end{tabular}

Values are expressed as mean \pm standard deviation, $\mathrm{n}=3$

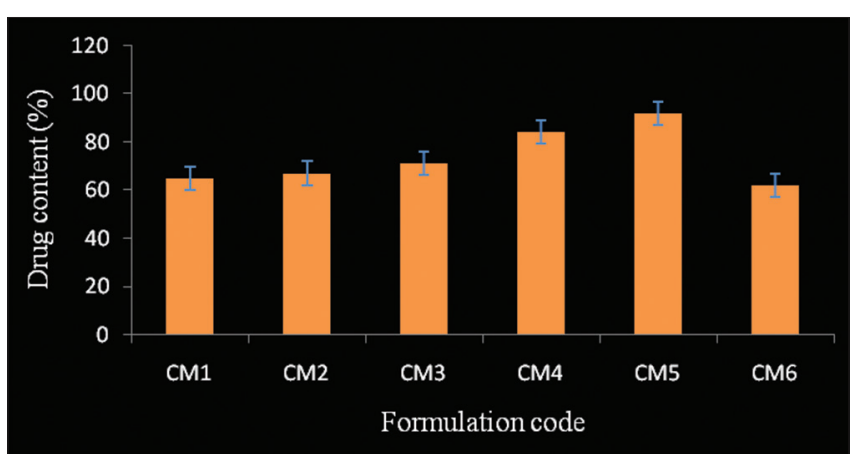

Fig. 8: Entrapment efficiency of microsphere formulations. Values are expressed as mean \pm standard deviation, $n=3$

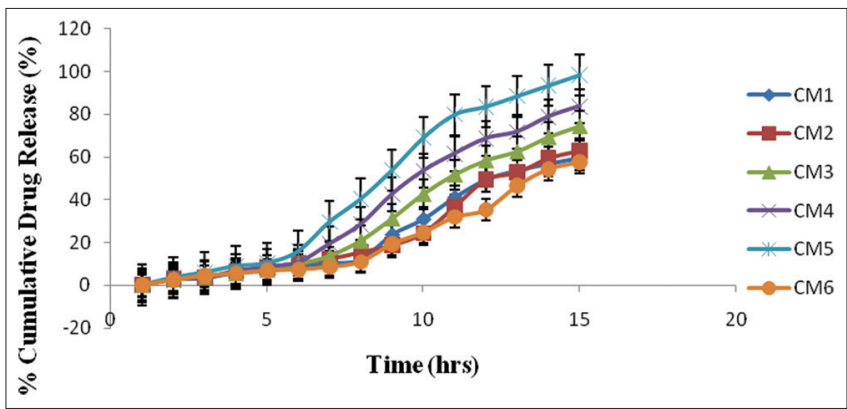

Fig. 9: In vitro drug release studies

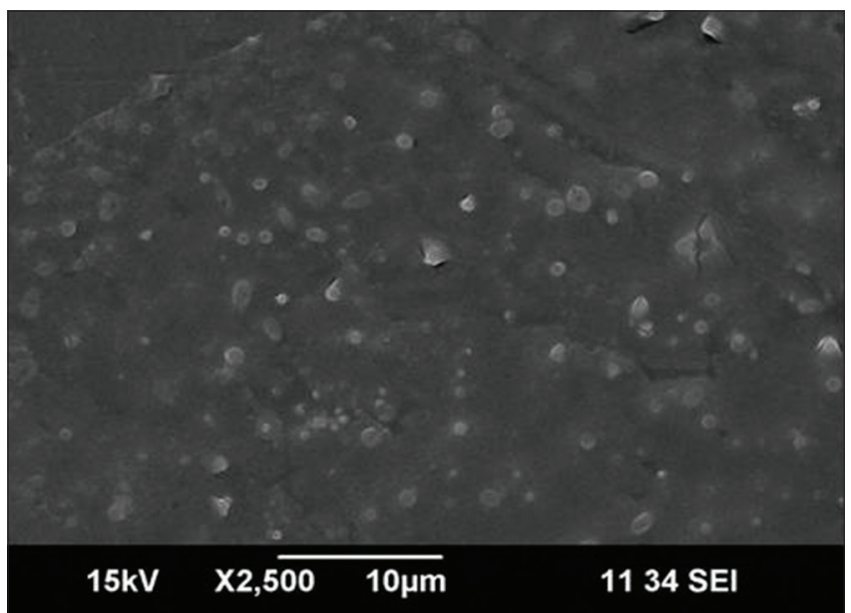

Fig. 10: Carbamazepine loaded rice bran wax microsphere (CM5)

In vitro drug release studies

The percentage of drug release from the prepared microspheres was studied by USP Type II paddle apparatus dissolution rate apparatus using Phosphate buffer pH 6.8 dissolution medium. The drug concentrations were determined spectrophotometric method at $285.5 \mathrm{~nm} .{ }^{21-23}$ CM5 formulation showed maximum controlled release shown in Fig. 9.

\section{SEM}

SEM was executed to examine the surface morphology of the microspheres. SEM images for CM5 formulation shown in Fig. 10 confirm spherical nature of microspheres with smooth surface. The average particle size of microspheres was around 2-5 $\mu \mathrm{m}$.

\section{CONCLUSION}

For fighting against epilepsy, a novel drug delivery system to combat this incurable firing disorder is yet to be developed. Antiepileptic medications are used as the first line treatment option, but conventional therapy is accompanied by a handful of side effects. This study aimed to develop CBZ sodium chitosan microspheres which could minimize the side effects by dose reduction and bypasses first pass metabolism. CBZ Na alginate microspheres have been prepared and evaluated. The CBZ Na alginate microspheres (CM5) shows adequate rheological, mucoadhesive and permeability properties. The suggested formula allows the drug CBZ to the rectal mucosa for subsequent sustained release behavior with no burst effect, which is a major disadvantage of CBZ immediate release systems. In vitro release kinetics of formulation clearly indicated that the CBZ microsphere exhibited zero order release. The study emerged as a successful attempt to reduce dosing frequency and drug-related adverse drug reaction by producing sustained releasing microspheres.

\section{REFERENCES}

1. Shivhareu D, Tijare PM. Formulation and characterization of microspheres of selected anti-Infective agent for urinary tract infection. J Drug Dev Res 2013;2(1):16-26.

2. Kreuter J, Nefzger M, Liehl E, Czok R, Voges R. Design and evaluation of microsphere: A review. J Pharm Sci 1983;46:7211.

3. Sugibayashi K, Akimoto M, Marmot Y, Nadai T, Kato Y. Microsphere as a novel drug delivery system. Pharmacobiodyn 1981;23:50.

4. Shanthi NC, Gupta R, Mahato KA. Traditional and emerging applications of microspheres: A review. Int J Pharm Tech Res 2010;2(1):675-81.

5. Najmuddin M, Ahmed A, Shelar S, Patel V, Khan T. Floating microspheres of ketoprofen: Formulation and evaluation. Int J Pharm PharmaSci 2010;2(2):83-7

6. Omkar T, Alagusundaram M, Madhu SC. Microspheres as a novel drug delivery system. Int J Chem Tech and Res 2009;3(1):526-34.

7. Wallace H, Shorvon S, Tallis R. Age-specific incidence and prevalence rates of treated epilepsy in an unselected population and age-specific fertility rates of women with epilepsy. Lancet 1998;352(9145):1970-3.

8. Engelborghs S, D'hooge R, Deyn PP. Pathophysiology of epilepsy. Acta Neurol Belg 2000;100(4):201-13.

9. Prabhakar S, Kharbanda PS. Antiepileptic drugs. J Indian Med Assoc 2002;100(5):304-9.

10. Prasanth VV, Moy AC, Mathew ST, Mathapan R. Microspheres-an overview. Int J Pharm Biomed Sci 2011;2(2):332-8.

11. Rajkumar M, Bhise SB. Carbamazepine-loaded porous microspheres for short-term sustained drug delivery. J Young Pharm 2010;2(1):07-14.

12. Mandal S, Mandal SD. Design and development of Carbamazepine mucoadhesive microemulsion for intranasal delivery: An ex vivo study. Int J PharmaSci Rev Res 2010;3:56-60.

13. Basarkar GD, Shirsath GN, Patil SB. Development of microspheres containing diclofenacdiethylamine as sustained release topical formulation. Bull Pharm Res 2013;3(1):14-22.

14. Ofokansi KC, Adikwu MU. Formulation and evaluation of microspheres based on gelatine-mucin admixtures for the rectal delivery of cefuroxime sodium. Trop J Pharm Res 2007;6(4):825-32.

15. Kobayashi Y, Ito S, Itai S, Yamamoto K. Physicochemical properties and bioavailability of Carbamazepine polymorphs and dihydrate. Int J Pharm 2000;193(2):137-46.

16. Rao NG, Kulkarni U. Development of carbamazepine fast dissolving tablets: Effect of functionality of hydrophillic carriers on solid 
dispersion technique. Asian J Pharm Clin Res 2010;3(2):114-7.

17. Sreeja CN, Anoop KR. Local antimicrobial delivery of satranidazole loaded cross linked periodontal chips using biodegradable polymers. Int J Pharm PharmSci 2013;5:839-47.

18. Revathy VN, Sreeja CN. Cross linked chitosan in situ gel of satranidazole for intra periodontal drug delivery. Int Res J Pharm 2014;5(4):239-43.

19. Aswathy SN, Vidhya KM, Saranya TR, Sreelakshmy KR, Sreeja CN. Mucoadhesivebuccal patch of cefiximetrihydrate using biodegradable natural polymer. Int J Pharm PharmSci 2014;6(6):366-71. 